\title{
Evaluation of Acute toxicity, In-vitro, In-vivo Antidiabetic Potential of the Flavonoid Fraction of the plant Chenopodium album L.
}

\author{
Neeraj Choudhary' ${ }^{1,2}$, Pranav Kumar Prabhakar', Gopal L. Khatik', Subba Rao Chamakuri', Devesh Tewari', \\ Ashish Suttee ${ }^{1, *}$
}

Neeraj Choudhary ${ }^{1,2}$, Pranav Kumar Prabhakar', Gopal L. Khatik', Subba Rao Chamakuri', Devesh Tewari', Ashish Suttee ${ }^{1, *}$

'School of Pharmaceutical Sciences, Lovely Professional University, Punjab, INDIA.

${ }^{2}$ Faculty of Pharmaceutical Sciences, PCTE

Group of Institutes, Ludhiana, Punjab, INDIA.

\section{Correspondence}

\section{Ashish Suttee}

School of Pharmaceutical Sciences, Lovely Professional University, Punjab, INDIA.

Phone no: +91-9814778316

E-mail: ashish7sattee@gmail.com

History

- Submission Date: 25-01-2021;

- Review completed: 15-02-2021;

- Accepted Date: 26-02-2021.

DOI : 10.5530/pj.2021.13.98

Article Available online

http://www.phcogj.com/v13/i3

\section{Copyright}

(C) 2021 Phcogj.Com. This is an openaccess article distributed under the terms of the Creative Commons Attribution 4.0 International license.

\begin{abstract}
Background: The Chenopodium album L. commonly recognized as Bathua, is widely distributed globally and contains various phytoconstituents that help treat several diseases. However, until now, aerial parts' antidiabetic potential and the plant's acute toxicity at fraction level have never been established. Objectives: To investigate the acute toxicity, the in-vitro, in-vivo antidiabetic potential of the plant at fraction level. Materials and Methods: The aerial parts of the plant were fractionated into different fractions, i.e., flavonoid fraction (CAFF), tannin fraction (CATF), alkaloid fraction (CAAF), saponin fraction (CASF), and were analyzed for in-vitro alpha-amylase inhibition assay. The CAFF, CATF, and CAAF were selected based on in-vitro alpha-amylase inhibition assay results and were further screened for its acute toxicity and in vivo antidiabetic activity using a high-fat diet and streptozotocin-induced diabetes model. The CAFF was characterized by LC-MS, and a molecular docking study was carried out. Results: The in-vitro alpha-amylase inhibition assay revealed that CAFF was found to be more potent than standard Acarbose having $I_{50}$ values $122.18 \pm 1.15$ and $812.83 \pm 1.07$ $\mu \mathrm{g} / \mathrm{ml}$, respectively. The CAFF fraction was found to possess potent antidiabetic activity in a dose-dependent manner in both in vitro and in vivo diabetic models and did not produce any sign of severe toxicity. Furthermore, the bioactive CAFF fraction was characterized by LC-MS, showed the presence of quercetin 3-O-(2",6"-di-O-rhamnosyl) glucoside (QRG) or quercetin 3-O-(2",6"-di-Orhamnosyl) galactoside (QRGa) and quercetin 3-O-rutinoside (rutin) (QR). It is predicted from the molecular docking study that the CAFF fraction primarily acts as an alphaamylase inhibitor. Conclusion: The CAFF fraction was found to poses dose-dependent potent antidiabetic activity and did not produce any sign of severe toxicity and primarily act as an alpha-amylase inhibitor.
\end{abstract}

Key words: Chenopodium album, Alpha-amylase, acute toxicity, antidiabetic activity, LC-MS, Molecular docking.

\section{INTRODUCTION}

Diabetes is one of the foremost causes of death across the globe ${ }^{1}$. In 2017, around 425 million adults in the age group of 20-79 years were reported to be affected by diabetes, and it is estimated to rise to 629 million by $2045^{2}$. Type 2 diabetes is a metabolic disorder characterized by hyperglycemia ${ }^{3-5}$ and also associated with the risk of cardiovascular disease and obesity ${ }^{6,7}$. Clinical evidence showed that improving lifestyle by maintaining healthy body weight and modest physical exercise can avoid Type 2 diabetes mellitus. Moreover, in a short time, lifestyle modification fails to exert its effects on diabetes, and it is tough to maintain the modified lifestyle ${ }^{8,9}$. Nowadays, combined therapy of several oral hypoglycemic agents exhibits an efficient treatment for glycemic control in the management of diabetes. However, the available combinational therapies possess numerous side effects ${ }^{10}$. The inclusion of phytoconstituents in combination therapy provides more efficient treatment with significantly decreased side effects in the management of diabetes ${ }^{11}$. Phytochemicals are considered less toxic compared with their synthetic counterparts ${ }^{12}$. Therefore, it is the need of the hour to explore phytochemicals for drug intervention that can help prevent and treat Type 2 diabetes mellitus with fewer side effects.

The Chenopodium album L. commonly known as Bathua in Hindi, is classified into the Chenopodiaceae family, widely grown globally, and contains various bioactive constituents that possess various therapeutic activities like anticancer hepatoprotective, antioxidant, antinociceptive activity, etc. ${ }^{13,14}$. The methanolic roots extract was earlier reported for the treatment of diabetes when evaluated using streptozotocin (STZ)-induced diabetes in Wistar rats ${ }^{15}$, and the aqueous extract of the aerial part of the C. album was showed considerable $\alpha$-amylase inhibition assay of $98.72 \%$ at $3 \mathrm{mg} / \mathrm{ml}$ of concentration ${ }^{16}$. However, the aerial parts' Bioactivity-guided fractionation was not evaluated for antidiabetic potential and acute toxicity study. This study pertains to investigate the potential fraction against the high-fat diet and STZ induced diabetic rat model and in-silico prediction of the possible mechanism of the bioactive fraction.

Cite this article: Choudhary N, Prabhakar PK, Khatik GL, Chamakuri SR, Tewari D, Suttee A. Evaluation of Acute toxicity, In-vitro, In-vivo Antidiabetic Potential of the Flavonoid Fraction of the plant Chenopodium album L. Pharmacog J. 2021;13(3): 765-79. 


\section{MATERIALS AND METHODS}

\section{Chemicals}

STZ was purchased from (CDH, New Delhi, India). Ingredients of feed such as cholesterol and casein from (CDH, New Delhi), formalin, sodium carboxymethylcellulose and L-cysteine (Loba Chemicals, Mumbai), yeast powder (Molychem, Mumbai), mineral and vitamin mix (Sarabhai chemicals, Baroda, India), Ghee (Patanjali, Haridwar), Acarbose (Sisco Research Laboratories Pvt. Ltd.).

\section{Collection and authentication of plant material}

Air-dried aerial parts of Chenopodium album L. was procured from the native areas of Ludhiana (Punjab), India, and was authenticated by Dr. Sunita Garg, Emeritus Scientist, Department of Raw Material Herbarium \& Museum, National Institute of Sciences Communication and Information Resources, New Delhi with the voucher specimen number NISCAIR/RHMD/Consult/2018/3227/28-1.

\section{Processing of the plant material}

The aerial part $(3000 \mathrm{~g})$ of $C$. album was collected on maturity, adequately cleaned, and was further air-dried at room temperature to prevent microbial growth, and after drying, the aerial parts were powdered using a mechanical grinder and preserved till further use in an airtight container.

\section{Fractionation of total tannins and flavonoids}

The powdered aerial parts were defatted using petroleum ether (40-60 ${ }^{\circ} \mathrm{C}$ ), followed by successive extraction with chloroform and ethyl acetate using microwave-assisted extraction. The dried ethyl acetate extract, which was then dissolved in the aqueous phase and $10 \% \mathrm{NaCl}$ solution, was added to the aqueous solution, centrifuge the solution to precipitate tannins (CATF), and further, the supernatant liquid was partitioned with ethyl acetate. The ethyl acetate layer was evaporated to dryness under reduced pressure to achieve the total flavonoids (CAFF) ${ }^{17}$.

\section{Fractionation of total alkaloids}

The aerial part of the plant was mixed with $\mathrm{NH}_{4} \mathrm{OH}(25 \%)$ to form a slurry, further extracted with ethyl acetate using microwave-assisted extraction. The dried ethyl acetate extract, dissolved in water acidified

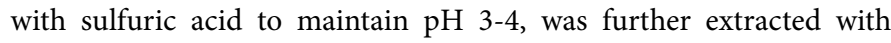
petroleum ether $\left(40-60{ }^{\circ} \mathrm{C}\right)$ followed by diethyl ether eliminate the lipophilic, acidic, and neutral impurities. The solution was basified to pH 9-10 with $\mathrm{NH}_{4} \mathrm{OH}$. The resulting solution was further extracted with chloroform and washed with distilled water, concentrated to dryness under reduced pressure to obtain total alkaloids $(\mathrm{CAAF})^{18}$.

\section{Fractionation of total saponin}

Defatting of the powdered aerial part was done as mentioned earlier, followed by successive extraction using chloroform and methanol as a solvent by microwave-assisted extraction. The dried methanolic extract was suspended in water, partitioning was done using diethyl ether and saturated $\mathrm{n}$-butanol to isolate the total saponin (CASF) ${ }^{19}$.

\section{In-vitro alpha-amylase inhibitory activity assay}

The alpha-amylase inhibitory assay was carried out using the iodinestarch method. Acarbose was used as a standard. The assay depends on developing an iodine and starch complex, i.e., blue, and exhibits maximum absorbance at $580 \mathrm{~nm}$. The positive control solution was prepared using alpha-amylase enzyme and starch in the absence of an inhibitor to achieving $100 \%$ enzymatic activity with minimum absorbance value. Whereas the negative control solution contains the starch that converts into the dark green colored complex after the addition of iodine solution having maximum absorbance due to the absence of inhibitor and alpha-amylase and possess no enzymatic activity. However, the test solution absorbance and color intensity should lie in the middle of positive and negative control absorbance ${ }^{20,21}$.

\section{Preparation of stock sample solution}

The stock solution $1000 \mathrm{ppm}$ concentration was prepared for each fraction (CAFF, CATF, CAAF, and CASF) by dissolving $10 \mathrm{mg}$ in 10 ml methanol.

\section{Preparation of sample solution}

The various sample concentrations were prepared by withdrawing $0.5,1,1.5,2$, and $2.5 \mathrm{ml}$ of the stock solution into $10 \mathrm{ml}$ of different volumetric flasks. Volume was prepared using methanol and labeled the sample solutions 50, 100,150, 200, and $250 \mu \mathrm{g} / \mathrm{ml}$.

$\%$ Inhibition and enzyme activity were calculated using the formula mentioned below:

Enzyme activity $=($ Abs. of negative control -Abs. of positive control)Abs. of test sample/

(Abs. of negative control- Abs. of positive control) ${ }^{\star} 100$

$\%$ Inhibition= 100-enzyme activity.

Inhibition concentration $\left(\mathrm{IC}_{50}\right)$ : The drug concentration where $50 \%$ enzyme inhibition takes place.

\section{Experimental animals}

Female albino mice were procured from the central animal facility from the Lala Lajpat Rai University of Veterinary and Animal Sciences, Hisar, for acute toxicity study. Sprague-Dawley (SD) rats of either sex procured from National Institutes of Pharmaceutical Education and Research, Mohali, for in-vivo antidiabetic study. The animals were kept in standard polypropylene cages and maintained under controlled conditions, i.e., room temperature $\left(22 \pm 2{ }^{\circ} \mathrm{C}\right)$ and relative humidity $(55 \pm 5 \%)$ with $12: 12 \mathrm{~h}$ light and dark cycle, and the experiments were conducted in the light cycle. All the rats and mice were supplied commercially accessible rat regular pellet diet (NPD) and water ad libitum before the dietary management. The animal experiments were conducted after approval from the Institutional Animal Ethics Committee of Lovely Professional University (Approval No. LPU/ IAEC/2019/53), and experiments were conducted as per the guidelines of CPSCEA (Govt. of India). For the acute toxicity, the female mice were selected as per the OECD test guidelines 425 , and for the antidiabetic activity, SD rats were selected for HFD and STZ induced diabetic rat model as per the reported literature ${ }^{24,25}$.

\section{Acute toxicity assay}

The acute toxicity assay was carried out as per the OECD Test Guidelines 425(Up and Down Procedure). The fractions (CAFF, CATF, and CAAF) were selected based on the in-vitro alpha-amylase assay results. In this study, non-pregnant female albino mice with an age group of 8-10 weeks and $28 \pm 4 \mathrm{~g}$ weight were selected. The mice fasted for 3-4 h before dosing but had access to water ad libitum and a single dose of $2000 \mathrm{mg} /$ kg; p.o of the fractions (CAFF, CATF, and CAAF) were administrated according to the bodyweight of the single mice from each test group. The animals were closely monitored initially for $30 \mathrm{~min}$, then for four $\mathrm{h}$ for any sign of toxicity. The food was restored after $1-2 \mathrm{~h}$ of dosing. After the drug-treated mouse's survival, all the remaining four mice in each group were administered with the same dose. A similar protocol was carried out for all the vehicle control group mice by administrating $1 \% \mathrm{CMC}$ in the same volume as the treated group. After the single-dose administration of all the fractions, the groups were closely monitored for any toxic effect, and behavioral parameters were also recorded for the first $30 \mathrm{~min}, 4 \mathrm{hrs}$, and $24 \mathrm{hrs}$ and after that at regular intervals 
14 days. The bodyweight of mice was measured at regular intervals. At the end of the protocol, the mice excised by cervical dislocation under general anesthesia and organ weight of heart, liver, and kidney were measured. Blood samples were withdrawn by cardiac puncture and sent to the pathology laboratory to estimate biochemical and hematological parameters. The isolated organs, i.e., heart, liver, and kidney, were preserved in $10 \%$ formalin solution for histopathology evaluation ${ }^{22,23}$.

\section{Biochemical analysis}

All the samples were sent to the pathology lab (National Laboratories, Phagwara, Punjab) to analyze blood glucose, triglyceride, cholesterol, HDL, LDL, VLDL, and creatinine urea, bilirubin, AST, ALT, alkaline phosphate, total protein, globulins, and albumin.

\section{Hematological analysis}

The blood samples were analyzed by pathology lab (National Laboratories, Phagwara, Punjab) in tubes containing EDTA for hematological study. CBC parameters, total $\mathrm{RBC}$, hemoglobin, $\mathrm{MCH}$, MCV, MCHC, WBC count, platelet count, lymphocytes, neutrophils, eosinophils, basophils, and monocytes were estimated.

\section{Histopathological study}

The isolated vital organs (heart, liver, and kidney) of mice were fixed in $10 \%$ formalin after sacrificing, after processing fixed in paraffin wax. Paraffin sections $(5 \mathrm{~mm}$ ) were stained with eosin and hematoxylin. The slides were kept beneath the light microscope, and magnified tissue structure images were captured for analysis.

\section{In-vivo antidiabetic activity}

\section{Diabetes induction and in vivo experimental design}

To evaluate and identify the potential novel antidiabetic agents from medicinal plants for the cure of type 2 diabetes mellitus, various fractions (CAFF, CATF, and CAAF) of C. album were selected using Sprague-Dawley rats (Both Male and Female) for the development of high-fat diet (HFD) feeding and administering a low dose $(35 \mathrm{mg} / \mathrm{kg})$ of Streptozotocin (STZ) $)^{22,23}$. The rats were categorized into two different dietary regimens, i.e., NPD or HFD composition ${ }^{26}$ (58\% fat, $25 \%$ protein, and $17 \%$ carbohydrate, as a percentage of total kcal) ad libitum, respectively, for the initial period of 2 weeks. The NPD and HFD rats were further divided into NPD, HFD + STZ, HFD + STZ + Test compound CAFF, CATF, and CAAF having six animals in each group. The ingredients of HFD are according to ${ }^{27}$. After two weeks of dietary manipulation, all the rats from the HFD-fed group were injected with STZ low dose ( $35 \mathrm{mg} / \mathrm{kg}$; i.p.). After that, body weight and biochemical estimations were conducted on the $7^{\text {th }}$ day. The test compounds CAFF, CATF, and CAAF, were fed orally at two different concentrations, i.e., $250 \mathrm{mg} / \mathrm{kg}$ and $500 \mathrm{mg} / \mathrm{kg}$ continuous for seven days. Therefore, the higher dose $(500 \mathrm{mg} / \mathrm{kg})$ was selected as per the previously reported literature of the plant ${ }^{15}$ and rationalized the study; the lower dose was selected, i.e., $250 \mathrm{mg} / \mathrm{kg}$. The blood samples were collected from rat's retro-orbital plexus under light anesthesia using capillary tubes to analyze the plasma glucose level, total cholesterol level, and triglycerides level. Histopathology of the pancreas was conducted after sacrificing $50 \%$ of the animals at the end of the protocol. The non-fasting rats with a plasma glucose level of $\geq 300 \mathrm{mg} \mathrm{dl}^{-1}$ were considered diabetic and chosen for further experimental studies. Animal feed water intake was also measured. The rats were allowed to continue with the feed as per the protocol.

\section{Histopathological study}

The rats' isolated pancreas was fixed in $10 \%$ formalin after sacrificing and processing, fixed in paraffin wax. $5 \mathrm{~mm}$ paraffin sections stained with eosin and hematoxylin. The slides were kept beneath the light microscope, and magnified tissue structure images were captured for analysis.

\section{Statistical analysis}

The results were expressed as Mean $\pm \mathrm{SD}$, and the statistical significance among the groups was analyzed by one-way analysis of variance (ANOVA) followed by Tukey's multiple comparison tests. $\mathrm{P} \leq 0.05$ was considered statistically significant.

\section{Liquid chromatography-mass spectrometry (LC-MS) analysis of CAFF}

The bioactive CAFF fraction obtained from the plant's aerial parts was characterized through LC-MS Spectra for the bioactive molecules responsible for the activity. The LC-MS data components present in the CAFF fraction correlated the mass fragments with reported literature data $^{28,29}$.

\section{Molecular docking}

The molecular modeling software, Autodock-vina ${ }^{30,31}$, was used to study molecular docking. PDB or proteins 3WY2, 4GQR, and 3SZ1 for alpha-glucosidase, alpha-amylase, and PPAR-gamma proteins were selected and extracted from the protein data bank. The structures of these molecules were drawn by ChemDraw and changed to 3D. Further minimizations of energy were carried out using the MM2 Interface program on ChemBio3D Ultra 12.0, and molecules were saved in pdb format (Cambridge Soft). For the identification of the most active molecule, initially, the removal of internal ligand was done and docking was carried out in the same manner as an actual ligand with set RMASD of $1.5 \mathrm{~A}^{\circ}$.

\section{RESULTS}

\section{Fractionation}

There were various fractions were obtained from the plant Chenopodium album. The yield of CAFF, CATF, CAAF, and CASF was 2.67, 2.74, 1.70, and $2.90 \%(\mathrm{w} / \mathrm{w})$.

\section{In-vitro Alpha-amylase inhibition assay}

All the fractions of the plant were evaluated by alpha-amylases assay. The CAFF showed potent alpha-amylase inhibitory activity when compared with standard Acarbose having IC $_{50}$ values $122.18 \pm 1.15$ and $812.83 \pm 1.07$ respectively, whereas the CATF, CAAF found to be less active with that of the standard in terms of $\%$ inhibition., The CASF was found to be least active in comparison to the other fractions. The results are mentioned in Table 1.

\section{Acute toxicity study}

The acute toxicity was conducted as per OECD Guidelines. CAFF, CATF, and CAAF at a concentration of $2000 \mathrm{mg} / \mathrm{kg}$ were evaluated. No mortality was observed in any of the treated and vehicle control groups. All the animals were observed at a regular interval, and observations were noted during the study phase, i.e., 14 days.

\section{Behavioral pattern and body weight}

The itching was observed in all the treated groups in the first $30 \mathrm{~min}$, and after that, sleepy and drowsing effects were observed in CAFF and CATF fraction during the first 4 hrs. The itching might be due to some mild toxicity caused by the fractions. During the acute toxicity study, it was observed that there is a slight increase in body weight in the treated and vehicle control group reported in Figure 1.

\section{Organ to body weight index}

There was no significant difference observed in organ to body weight index for both treated and vehicle control groups. There were no lesions 
Table 1: Represents the $\%$ inhibition and $I C_{50}$ of fractions from Chenopodium album.

\begin{tabular}{|c|c|c|c|c|c|c|c|}
\hline S. No & Conc. $(\mu \mathrm{g} / \mathrm{ml})$ & Log Conc. & $\begin{array}{c}\% \text { Inhibition } \\
\text { Acarbose }\end{array}$ & $\begin{array}{c}\% \text { Inhibition } \\
\text { CAFF }\end{array}$ & $\begin{array}{c}\% \text { Inhibition } \\
\text { CATF }\end{array}$ & $\begin{array}{c}\% \text { Inhibition } \\
\text { CAAF }\end{array}$ & $\begin{array}{c}\% \text { Inhibition } \\
\text { CASF }\end{array}$ \\
\hline 1 & 50 & 1.70 & $8.75 \pm 0.67$ & $27.63 \pm 0.93$ & $7.89 \pm 0.74$ & $3.29 \pm 0.87$ & $2.63 \pm 0.88$ \\
\hline 2 & 100 & 2.00 & $17.86 \pm 0.87$ & $40.13 \pm 0.79$ & $11.84 \pm 0.79$ & $5.26 \pm 0.78$ & $3.29 \pm 0.72$ \\
\hline 3 & 150 & 2.18 & $21.32 \pm 0.53$ & $51.97 \pm 1.02$ & $16.45 \pm 0.98$ & $7.24 \pm 0.99$ & $4.61 \pm 0.68$ \\
\hline 4 & 200 & 2.30 & $28.12 \pm 0.78$ & $63.82 \pm 0.87$ & $21.05 \pm 0.86$ & $9.21 \pm 1.07$ & $5.92 \pm 0.57$ \\
\hline \multirow[t]{2}{*}{5} & 250 & 2.40 & $34.67 \pm 0.97$ & $75.66 \pm 0.68$ & $26.97 \pm 0.91$ & $10.53 \pm 1.02$ & $6.58 \pm 0.71$ \\
\hline & $\mathrm{IC}_{50(\mu \mathrm{g} / \mathrm{mL})}$ & & $812.83 \pm 1.07$ & $122.18 \pm 1.15$ & ---- & ---- & --- \\
\hline
\end{tabular}

Values are expressed as Mean \pm SD; CAFF- Chenopodium album flavonoid fraction; CATF- Chenopodium album tannin fraction; CAAF- Chenopodium album alkaloid fraction; CASF- Chenopodium album saponin fraction.

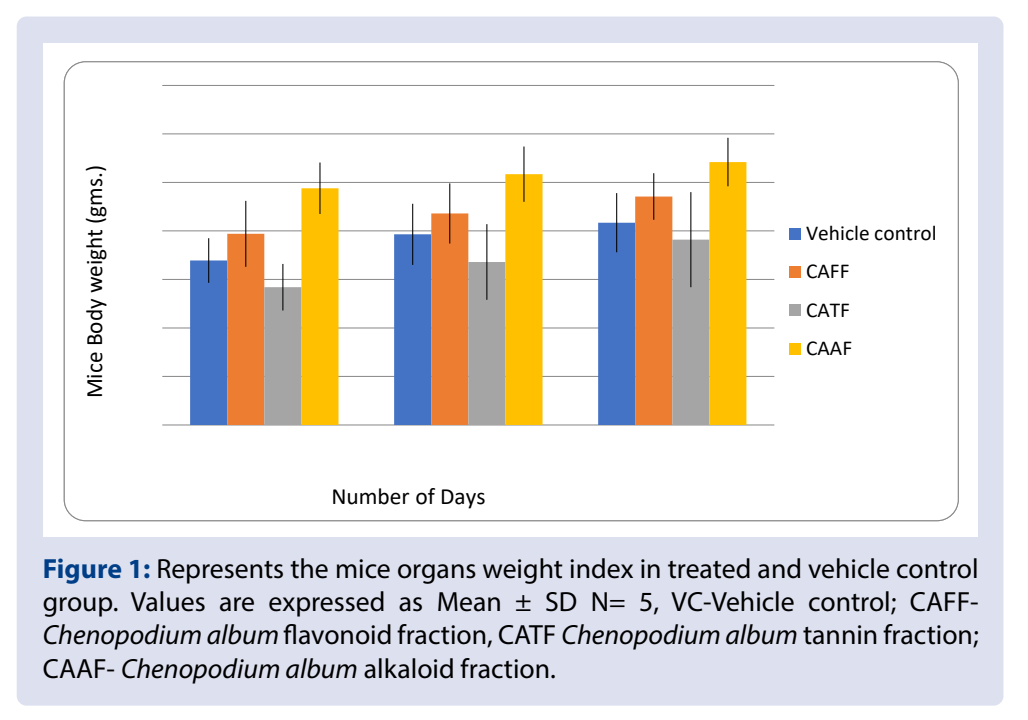

observed at the organ level (heart, liver, and kidney) in any of the groups at a $2000 \mathrm{mg} / \mathrm{kg}$ concentration, p.o. The organ to body weight index was recorded and reported in Figure 2.

\section{Biochemical analysis}

In CAFF fraction, there is an increase in the total cholesterol, HDL, LDL, VLDL, triglycerides, urea, creatinine, protein, SGOT, SGPT levels when compared with vehicle control. Furthermore, in the CATF fraction, the levels of the total cholesterol, LDL, Triglycerides, urea, protein, SGOT, ALP were also increased, whereas in the CAAF fraction, there is an increase in total cholesterol, LDL, urea, SGOT, and ALP levels were recorded. The biochemical results indicate that all the fractions at $2000 \mathrm{mg} / \mathrm{kg}$ produce mild toxicity symptoms in albino mice without producing any severe toxicity at the organ level. The data are represented in Table 2.

\section{Hematological analysis}

Both fractions CAFF and CATF causes an increase in the levels of HGB, RBC, HCT, MCV, MCH, MCHC, PLT, PDW, MPV, and PCT, whereas the CAAF fraction significantly increases the levels of RBC, HCT, $\mathrm{MCV}, \mathrm{MCH}, \mathrm{MCHC}, \mathrm{WBC}, \mathrm{PLT}, \mathrm{PDW}, \mathrm{MPV}$, and P-LCR. The research finding of a hematologic evaluation represents that all the fractions produce only mild toxicity symptoms in albino mice. The hematology data are represented in Table 3.

\section{Histopathology analysis}

All the fractions CAFF, CATF, and CAAF of the plant did not show any severe sign of toxicity at the organ level, suggesting that all the fractions are safe at a concentration of $2000 \mathrm{mg} / \mathrm{kg}$, p.o. The histopathological research findings are summarized for the heart (Figure 3), Kidney (Figure 4), and liver (Figure 5). The results indicate that all the plant fractions produce only mild toxicity at the heart, liver, and kidney, but the CAAF fraction produces mild to moderate liver toxicity. These results are also supported by the organ to body weight index, biochemical and hematology findings.

\section{In-vivo Antidiabetic activity}

\section{Biochemical analysis}

The plasma glucose, total cholesterol, and total triglycerides were compared on the $22^{\text {nd }}$ and $29^{\text {th }}$ day reported in Table 4 . After one week of STZ injection, i.e., on the $22^{\text {nd }}$ day, there is a highly significant increase in glucose, cholesterol, and triglyceride level in all the HFD+STZ treated groups that confirm the type 2 diabetic condition. After one week of treatment, i.e., $29^{\text {th }}$ day, there is a highly significant decrease in the glucose, cholesterol, and triglyceride level in a CAFF fraction at a dose of $500 \mathrm{mg} / \mathrm{kg}$, p.o. when compared with the experimental group and found to be more potent than the standard Acarbose. Furthermore, the CATF fraction also significantly reduces all the biochemical levels when compared with the experimental group. There is no significant difference observed with the CAAF fraction treated group than the experimental group (Figure 6).

\section{Histopathology analysis}

After a single dose of STZ administration, there is the development of type- 2 diabetes and leads to necrosis of $\beta$-cell, which can be observed in the experimental group. After a week of administration of the CAFF fraction, the organs were isolated on the $29^{\text {th }}$ day. The findings represented that the islet of pancreatic cells retains their standard structure, and mild necrosis was observed that supports the CAFF fraction's potential antidiabetic effect, whereas, in the CATF fraction, there is less recovery of islet cell. However, no recovery was observed in the CAAF treated group than the experimental control group (Figure 7). 


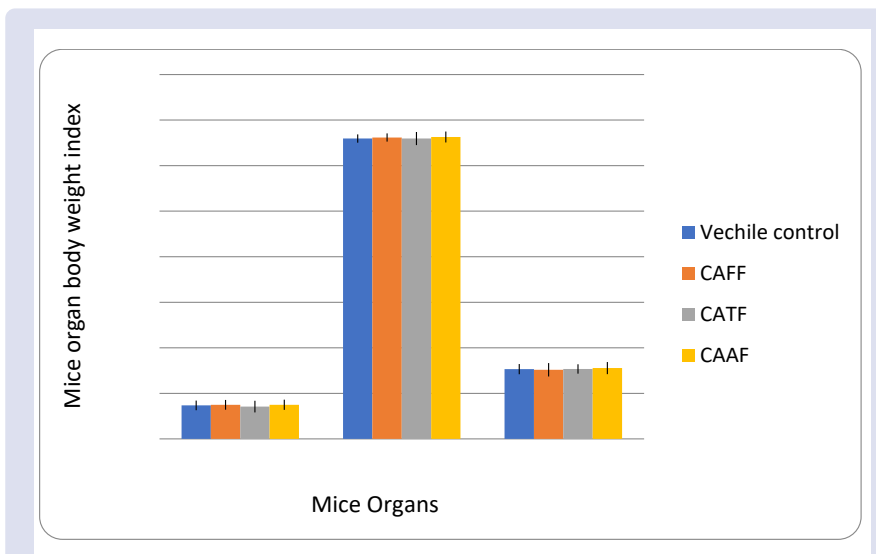

Figure 2: Effects of the Chenopodium album fractions on the body weight of mice. Values are presented as Mean $\pm S D, N=5$; Organ-to-body weight index $=$ (organ weight $\times 100)$ /body weight VC-Vehicle control; CAFFChenopodium album flavonoid fraction, CATF Chenopodium album tannin fraction; CAAF- Chenopodium album alkaloid fraction.

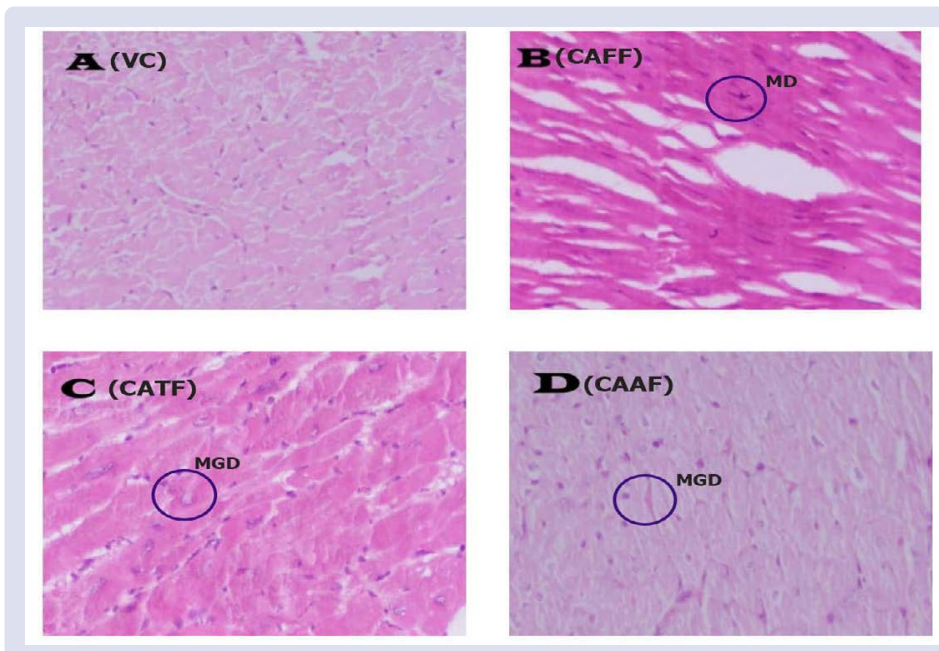

Figure 3: Represents the Histopathological observations of Heart, A (VC): Nothing abnormal detected; $B(C A F F)$ : Mild degenerative changes in the myocardial fibers; C (CATF): Mild granular degeneration in the myocardial fibers; $\mathrm{D}$ (CAAF): Mild granular degeneration in the myocardial fibers.
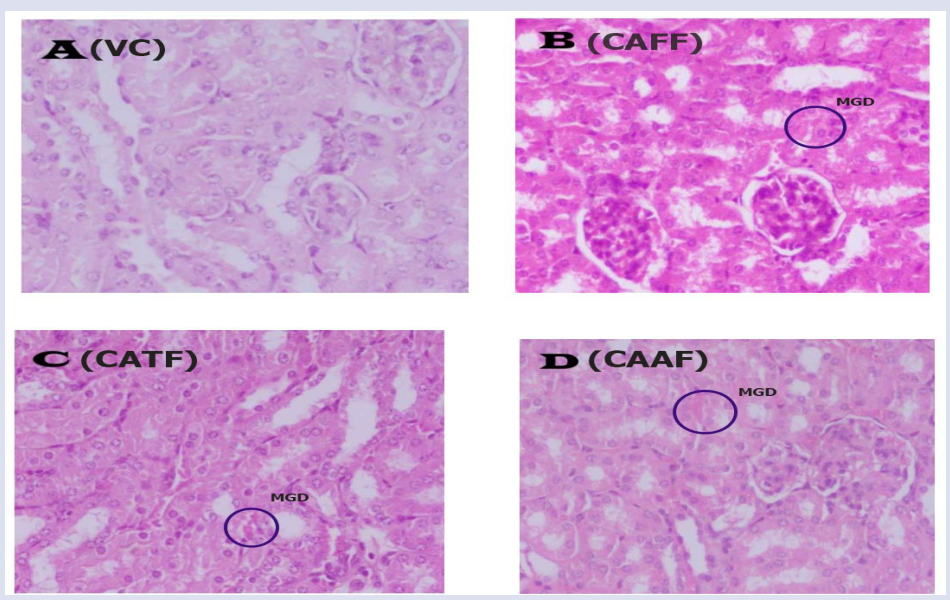

Figure 4: Represents the Histopathological observations of Kidney, A (VC): Nothing abnormal detected; B(CAFF): Mild granular degeneration and necrosis of the tubular epithelial cells; C (CATF): Mild granular degeneration and necrosis of the tubular epithelial cells; D (CAAF): Mild granular degeneration and necrosis of the tubular epithelial cells. 


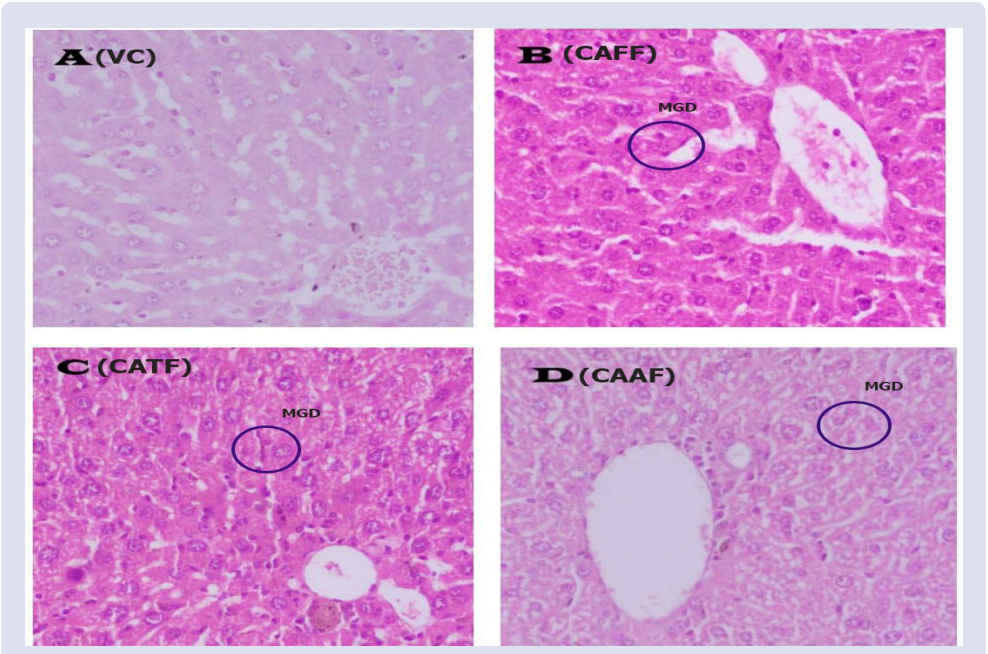

Figure 5: Represents the Histopathological observations of liver, A (VC): Nothing abnormal detected; $\mathrm{B}(\mathrm{CAFF})$ : Mild granular degeneration in hepatocyctes of the liver; $C$ (CATF): Mild fatty changes and granular degeneration in hepatocyctes of the liver; D (CAAF): Mild to moderate granular degeneration in hepatocyctes of the liver.

Table 2: Represents the Biochemical analysis of various fractions of Chenopodium album.

\begin{tabular}{|c|c|c|c|c|c|c|}
\hline S. No & PARAMETERS & Units & VC & CAFF & CATF & CAAF \\
\hline 1 & GLUCOSE & $\mathrm{mg} / \mathrm{dl}$ & $94.67 \pm 1.96$ & $91.37 \pm 3.31$ & $92.44 \pm 2.88$ & $95.54 \pm 3.73$ \\
\hline \multicolumn{7}{|c|}{ LIPID PROFILE } \\
\hline 2 & TOTALCHOLESTEROL & $\mathrm{mg} / \mathrm{dl}$ & $98.67 \pm 3.06$ & $187.67 \pm 2.52 \#$ & $108.00 \pm 0.61 \#$ & $117.00 \pm 2.00 \#$ \\
\hline 3 & HDL CHOLESTEROL & $\mathrm{mg} / \mathrm{dl}$ & $30.33 \pm 1.53$ & $44.80 \pm 0.26 \#$ & $31.70 \pm 0.61$ & $32.23 \pm 1.59$ \\
\hline 4 & LDL CHOLESTEROL & $\mathrm{mg} / \mathrm{dl}$ & $45.93 \pm 1.51$ & $117.13 \pm 1.42 \#$ & $55.35 \pm 1.71 \#$ & $62.43 \pm 2.33 \#$ \\
\hline 5 & VLDL CHOLESTEROL & $\mathrm{mg} / \mathrm{dl}$ & $22.40 \pm 0.60$ & $25.73 \pm 1.10 \#$ & $21.25 \pm 1.26$ & $22.33 \pm 0.70$ \\
\hline 6 & TRIGLYCERIDES & $\mathrm{mg} / \mathrm{dl}$ & $112 \pm 3.00$ & $128.67 \pm 5.51 \#$ & $106.27 \pm 6.29 \#$ & $111.67 \pm 3.51$ \\
\hline 7 & CHOL/HDL RATIO & & $3.26 \pm 0.11$ & $4.19 \pm 0.03 \#$ & $3.42 \pm 0.06$ & $3.64 \pm 0.21 \#$ \\
\hline 8 & LDL/HDL RATIO & & $1.52 \pm 0.08$ & $2.61 \pm 0.02 \#$ & $1.75 \pm 0.06 \#$ & $1.94 \pm 0.15 \#$ \\
\hline \multicolumn{7}{|c|}{ KIDNEY FUNCTION TESTS } \\
\hline 9 & UREA & $\mathrm{mg} / \mathrm{dl}$ & $37.33 \pm 2.08$ & $54.00 \pm 2.00 \#$ & $56.00 \pm 2.65 \#$ & $60.00 \pm 2.00 \#$ \\
\hline 10 & CREATININE & $\mathrm{mg} / \mathrm{dl}$ & $0.53 \pm 0.02$ & $0.60 \pm 0.02 \#$ & $0.57 \pm 0.03$ & $0.57 \pm 0.02$ \\
\hline \multicolumn{7}{|c|}{ LIVER FUNCTION TESTS } \\
\hline 11 & BIT & $\mathrm{mg} / \mathrm{dl}$ & $0.67 \pm 0.06$ & $0.90 \pm 0.05 \#$ & $0.61 \pm 0.07$ & $0.78 \pm 0.09$ \\
\hline 12 & BID & $\mathrm{mg} / \mathrm{dl}$ & $0.25 \pm 0.05$ & $0.30 \pm 0.05$ & $0.26 \pm 0.06$ & $0.35 \pm 0.05 \#$ \\
\hline 13 & BII & $\mathrm{mg} / \mathrm{dl}$ & $0.42 \pm 0.02$ & $0.60 \pm 0.10 \#$ & $0.34 \pm 0.07$ & $0.44 \pm 0.04$ \\
\hline 14 & PROTEIN & $\mathrm{mg} / \mathrm{dl}$ & $6.27 \pm 0.21$ & $7.03 \pm 0.11 \#$ & $6.46 \pm 0.06 \#$ & $6.23 \pm 0.12$ \\
\hline 15 & ALBUMIN & $\mathrm{mg} / \mathrm{dl}$ & $2.27 \pm 0.06$ & $2.95 \pm 0.05 \#$ & $2.57 \pm 0.06 \#$ & $2.62 \pm 0.06 \#$ \\
\hline 16 & GLOBULIN & $\mathrm{mg} / \mathrm{dl}$ & $4.00 \pm 0.17$ & $4.08 \pm 0.13$ & $3.90 \pm 0.04$ & $3.61 \pm 0.10 \#$ \\
\hline 17 & A:G/RATIO & & $0.57 \pm 0.02$ & $0.72 \pm 0.03 \#$ & $0.66 \pm 0.02 \#$ & $0.72 \pm 0.02 \#$ \\
\hline 18 & SGOT/AST & $\mathrm{IU} / \mathrm{L}$ & $95.93 \pm 1.79$ & $151.00 \pm 8.19 \#$ & $137.00 \pm 2.65 \#$ & $125.10 \pm 4.01 \#$ \\
\hline 19 & SGPT/ALT & $\mathrm{IU} / \mathrm{L}$ & $65.97 \pm 5.31$ & $68.45 \pm 4.30$ & $65.37 \pm 4.30$ & $64.96 \pm 4.38$ \\
\hline 20 & ALP & $\mathrm{IU} / \mathrm{L}$ & $94.97 \pm 6.05$ & $128.33 \pm 6.03 \#$ & $124.67 \pm 3.51 \#$ & $129.67 \pm 4.16 \#$ \\
\hline
\end{tabular}

Values are presented as Mean $\pm \mathrm{SD}, \mathrm{N}=5$, Statistical analysis was performed using one way ANOVA followed by Turkey's multiple comparison test, \# represents $\mathrm{P}<0.05$ vs. Vehicle Control; VC-Vehicle control; CAFF- Chenopodium album flavonoid fraction, CATF Chenopodium album tannin fraction; CAAF- Chenopodium album alkaloid fraction.

\section{Characterization by LC-MS}

The in-vitro and in-vivo results showed that the CAFF possesses maximum activity among all the plant fractions. The CAFF fraction was analyzed by LC-MS Spectra and predicted two possible structures at retention time $7.13 \mathrm{~min}$ are Quercetin 3-O-(2",6"-di-O-rhamnosyl) glucoside (QRG) or Quercetin 3-O-(2",6"-di-Orhamnosyl) galactoside (QRGa) and 7.62 min. for Quercetin 3-O-rutinoside (rutin) (QR), as the major constituents that can be responsible for its activity Table 5 .

\section{Molecular docking}

Based on LC-MS's prediction, major constituents were studied insilico for their antidiabetic activity choosing a-glucosidase, $\alpha$-amylase, and PPAR gamma receptors. Among the phytochemicals, QRGa is supposed to be most active with $-6.5 \mathrm{kcal} / \mathrm{mol},-9.3 \mathrm{kcal} / \mathrm{mol}$, and -7.0 $\mathrm{kcal} / \mathrm{mol} \alpha$-glucosidase, $\alpha$-amylase, and PPAR gamma, respectively in comparison to standard Acarbose as mentioned in Table 6. A detailed interaction for QRGa was studied for $\alpha$-glucosidase, $\alpha$-amylase, and 


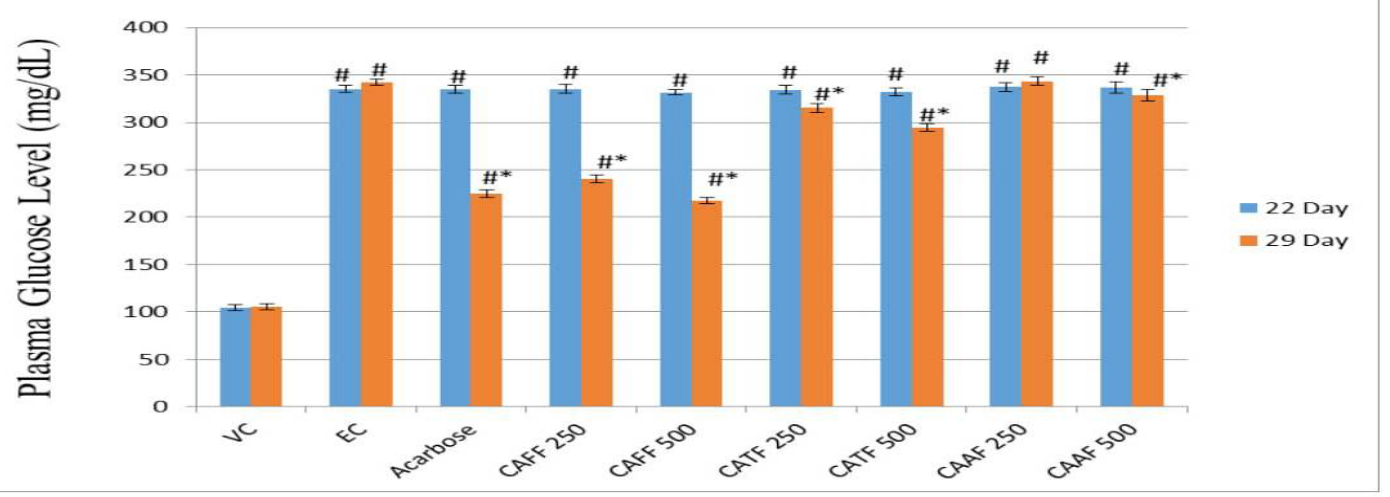

(a)

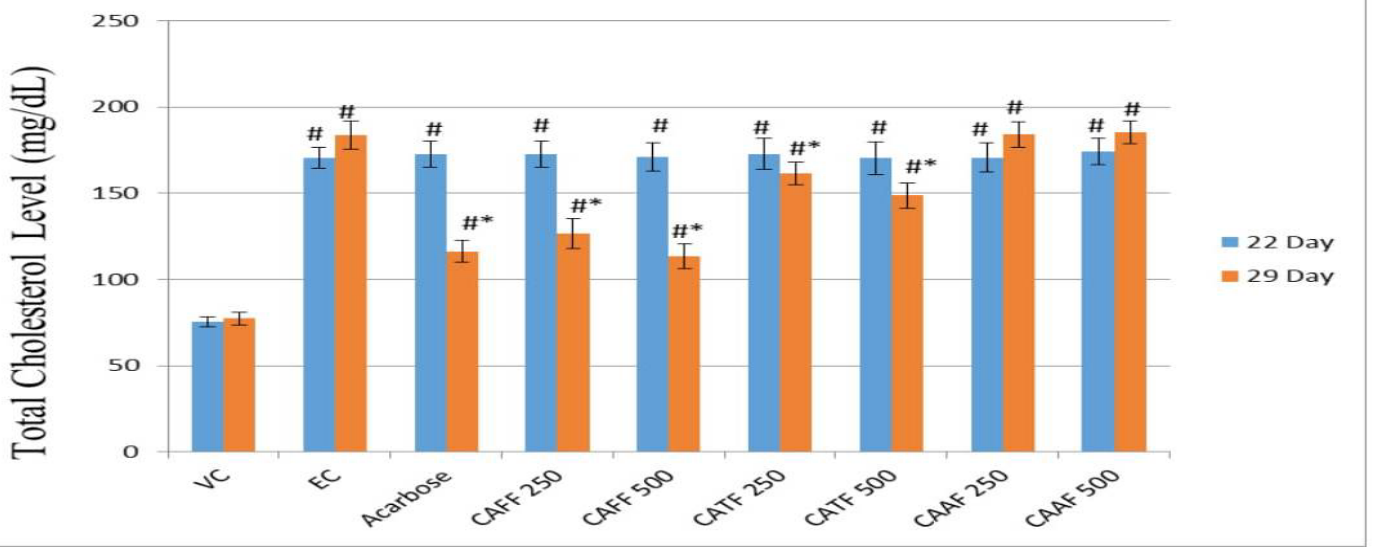

(b)

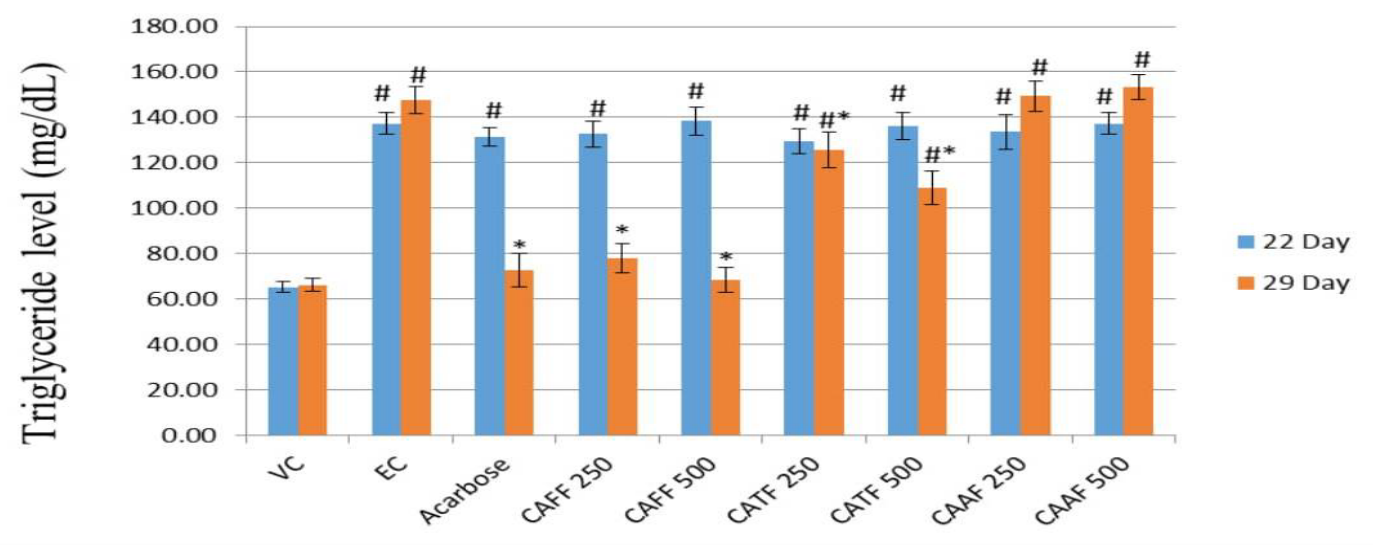

(c)

Figure 6: Effect of different groups on plasma glucose level (a), total cholesterol (b) and triglycerides (c). Values are presented as Mean $\pm \mathrm{SD}, \mathrm{n}=6$. Statistical analysis was performed using one way ANOVA followed by Turkey's multiple comparison test, \# represents $p<0.05$ vs. Vehicle Control, * represents $p<0.05$ vs. Experimental Control; NPD: Normal pallet diet; CMC: Carboxymethyl cellulose; HFD: High fat Diet; CAFF- Chenopodium album flavonoid fraction; CATF Chenopodium album tannin fraction; CAAFChenopodium album alkaloid fraction. 
Table 3: Represents the Hematological analysis of various fractions of Chenopodium album.

\begin{tabular}{|c|c|c|c|c|c|c|}
\hline S. No & Parameters & Unit & VC & CAFF & CATF & CAAF \\
\hline 1 & HGB & $\mathrm{g} / \mathrm{dl}$ & $13.35 \pm 0.05$ & $15.48 \pm 0.08 \#$ & $15.32 \pm 0.08 \#$ & $13.40 \pm 0.05$ \\
\hline 2 & RBCs & $10^{6} / \mathrm{ul}$ & $8.48 \pm 0.08$ & $9.68 \pm 0.04 \#$ & $10.05 \pm 0.04 \#$ & $8.70 \pm 0.03 \#$ \\
\hline 3 & HCT & $\%$ & $44.68 \pm 0.16$ & $53.30 \pm 0.11 \#$ & $52.69 \pm 0.10 \#$ & $47.42 \pm 0.08 \#$ \\
\hline 4 & $\mathrm{MCV}$ & $\mathrm{fL}$ & $52.67 \pm 0.52$ & $55.08 \pm 0.09 \#$ & $52.41 \pm 0.09$ & $54.53 \pm 0.08 \#$ \\
\hline 5 & $\mathrm{MCH}$ & $\mathrm{Pg}$ & $15.74 \pm 0.19$ & $16.00 \pm 0.02 \#$ & $15.24 \pm 0.02 \#$ & $15.41 \pm 0.01 \#$ \\
\hline 6 & $\mathrm{MCHC}$ & $\mathrm{g} / \mathrm{dl}$ & $29.88 \pm 0.07$ & $29.05 \pm 0.09 \#$ & $29.07 \pm 0.09 \#$ & $28.26 \pm 0.06 \#$ \\
\hline 7 & RDW-SD & $\mathrm{fL}$ & $19.69 \pm 0.11$ & $21.80 \pm 0.05 \#$ & $22.76 \pm 0.06 \#$ & $22.27 \pm 0.07 \#$ \\
\hline 8 & RDW-CV & $\%$ & $19.06 \pm 0.05$ & $21.87 \pm 0.08 \#$ & $20.66 \pm 0.06 \#$ & $20.80 \pm 0.09 \#$ \\
\hline 9 & WBCs & $10^{3} / \mathrm{ul}$ & $4.94 \pm 0.03$ & $4.95 \pm 0.04$ & $4.89 \pm 0.03$ & $4.81 \pm 0.04 \#$ \\
\hline 10 & NEUT\% & $\%$ & $20.45 \pm 0.41$ & $20.61 \pm 0.92$ & $21.45 \pm 0.79$ & $21.00 \pm 0.26$ \\
\hline 11 & LYMPH\% & $\%$ & $76.37 \pm 0.33$ & $75.52 \pm 0.91$ & $76.40 \pm 0.77$ & $74.96 \pm 0.34 \#$ \\
\hline 12 & MONO\% & $\%$ & $1.00 \pm 0.12$ & $1.37 \pm 0.05$ \# & $1.31 \pm 0.09 \#$ & $1.32 \pm 0.07 \#$ \\
\hline 13 & $\mathrm{EO} \%$ & $\%$ & $2.18 \pm 0.12$ & $2.50 \pm 0.05 \#$ & $2.64 \pm 0.03 \#$ & $2.72 \pm 0.04 \#$ \\
\hline 14 & BASO $\%$ & $\%$ & $0.00 \pm 0.00$ & $0.00 \pm 0.00$ & $0.00 \pm 0.00$ & $0.00 \pm 0.00$ \\
\hline 15 & $\mathrm{IG} \%$ & $\%$ & $0.00 \pm 0.00$ & $0.00 \pm 0.00$ & $0.00 \pm 0.00$ & $0.00 \pm 0.00$ \\
\hline 16 & NEUT\# & $10^{3} / \mathrm{ul}$ & $1.01 \pm 0.02$ & $1.02 \pm 0.04$ & $1.05 \pm 0.04$ & $1.01 \pm 0.01$ \\
\hline 17 & LYMPH\# & $10^{3} / \mathrm{ul}$ & $3.78 \pm 0.03$ & $3.74 \pm 0.07$ & $3.65 \pm 0.04 \#$ & $3.61 \pm 0.03 \#$ \\
\hline 18 & MONO\# & $10^{3} / \mathrm{ul}$ & $0.05 \pm 0.01$ & $0.07 \pm 0.00$ \# & $0.06 \pm 0.00$ & $0.06 \pm 0.00$ \\
\hline 19 & $\mathrm{EO \#}$ & $10^{3} / \mathrm{ul}$ & $0.11 \pm 0.01$ & $0.12 \pm 0.00$ & $0.13 \pm 0.00$ & $0.13 \pm 0.00$ \\
\hline 20 & BASO\# & $10^{3} / \mathrm{ul}$ & $0.00 \pm 0.00$ & $0.00 \pm 0.00$ & $0.00 \pm 0.00$ & $0.00 \pm 0.00$ \\
\hline 21 & IG\# & $10^{3} / \mathrm{ul}$ & $0.00 \pm 0.00$ & $0.00 \pm 0.00$ & $0.00 \pm 0.00$ & $0.00 \pm 0.00$ \\
\hline 22 & PLT & $10^{3} / \mathrm{ul}$ & $692.33 \pm 2.52$ & $821.67 \pm 6.51 \#$ & $779.00 \pm 4.58 \#$ & $705.00 \pm 3.00 \#$ \\
\hline 23 & PDW & $\mathrm{fL}$ & $6.75 \pm 0.05$ & $7.34 \pm 0.04 \#$ & $6.92 \pm 0.03 \#$ & $6.83 \pm 0.04 \#$ \\
\hline 24 & MPV & $\mathrm{fL}$ & $6.25 \pm 0.05$ & $6.50 \pm 0.03 \#$ & $6.56 \pm 0.06 \#$ & $6.45 \pm 0.05 \#$ \\
\hline 25 & P-LCR & $\%$ & $3.04 \pm 0.01$ & $3.82 \pm 0.02 \#$ & $3.41 \pm 0.04 \#$ & $3.15 \pm 0.05 \#$ \\
\hline 26 & PCT & $\%$ & $0.51 \pm 0.02$ & $0.75 \pm 0.03 \#$ & $0.56 \pm 0.01 \#$ & $0.49 \pm 0.02$ \\
\hline
\end{tabular}

Values are presented as Mean $\pm \mathrm{SD}, \mathrm{N}=5$, Statistical analysis was performed using one way ANOVA followed by Turkey's multiple comparison test, \# represents $\mathrm{P}<0.050$ vs. Vehicle Control; VC-Vehicle control; CAFF- Chenopodium album flavonoid fraction; CATF Chenopodium album tannin fraction; CAAF- Chenopodium album alkaloid fraction.

Table 4: Represents the plasma glucose level, total cholesterol and triglyceride level in SD Rats.

\begin{tabular}{|c|c|c|c|c|c|c|}
\hline \multirow{2}{*}{ Group Number } & \multicolumn{2}{|c|}{ Plasma glucose level (mg/dL) } & \multicolumn{2}{|c|}{ Total Cholesterol level (mg/dL) } & \multicolumn{2}{|c|}{ Triglyceride level (mg/dL) } \\
\hline & 22 Day & 29 Day & 22 Day & 29 Day & 22 Day & 29 Day \\
\hline I & $104.33 \pm 3.06$ & $105.33 \pm 3.06$ & $75.33 \pm 3.06$ & $77.33 \pm 3.79$ & $65.33 \pm 2.52$ & $66.33 \pm 3.06$ \\
\hline II & $335.33 \pm 3.51 \#$ & $342.33 \pm 2.52 \#$ & $170.33 \pm 6.03 \#$ & $183.67 \pm 8.08$ \# & $137.33 \pm 4.73 \#$ & $147.67 \pm 6.11 \#$ \\
\hline III & $334.67 \pm 4.16 \#$ & $224.33 \pm 3.51 * \#$ & $172.67 \pm 7.51 \#$ & $116.33 \pm 6.11 * \#$ & $131.33 \pm 4.16 \#$ & $72.67 \pm 7.37$ * \\
\hline IV & $335.33 \pm 4.51 \#$ & $240.33 \pm 4.51 * \#$ & $172.67 \pm 7.64 \#$ & $126.67 \pm 8.50^{\star} \#$ & $130.67 \pm 3.79 \#$ & $78.00 \pm 6.56^{*}$ \\
\hline $\mathrm{V}$ & $331.67 \pm 3.06 \#$ & $217.33 \pm 3.51 * \#$ & $171.00 \pm 8.19 \#$ & $113.33 \pm 7.02 * \#$ & $134.33 \pm 5.69 \#$ & $68.33 \pm 5.51 *$ \\
\hline VI & $334.33 \pm 4.73 \#$ & $315.33 \pm 3.06^{\star} \#$ & $172.67 \pm 9.02 \#$ & $161.33 \pm 6.51^{\star} \#$ & $129.67 \pm 5.51 \#$ & $125.67 \pm 8.02$ *\# \\
\hline VII & $332.33 \pm 4.16 \#$ & $294.33 \pm 5.69 * \#$ & $170.33 \pm 9.61 \#$ & $148.67 \pm 7.37{ }^{\star} \#$ & $136.33 \pm 6.03 \#$ & $109.00 \pm 7.55^{\star} \#$ \\
\hline VIII & $337.33 \pm 4.73 \#$ & $343.33 \pm 4.51 \#$ & $170.67 \pm 8.50 \#$ & $184.00 \pm 7.55 \#$ & $133.67 \pm 7.51 \#$ & $149.33 \pm 6.51 \#$ \\
\hline IX & $336.67 \pm 5.86 \#$ & $328.33 \pm 3.51 \star \#$ & $174.33 \pm 7.64 \#$ & $185.33 \pm 6.66 \#$ & $137.33 \pm 4.73 \#$ & $153.33 \pm 5.51 \#$ \\
\hline
\end{tabular}

Values are presented as Mean $\pm \mathrm{SD}, \mathrm{n}=6$. Statistical analysis was performed using one way ANOVA followed by Turkey's multiple comparison test, \# represents $\mathrm{p}<$ 0.05 vs. Vehicle Control, ${ }^{*}$ represents $\mathrm{p}<0.05$ vs. Experimental Control.

PPAR gamma, respectively. QRGa showed four hydrogen bonding to ASN301 at the binding site of alpha-glucosidase (Figure 8a), while electrostatic interactions with alpha-amylase (Figure 8b), QRGa showed one hydrogen bond with PPAR-gamma protein (Figure 8c). The RMSD set for molecular docking was $1.5 \mathrm{~A}^{\circ}$.

\section{DISCUSSION}

Type 2 Diabetes mellitus is the most common type of diabetes that arises from insulin production defects or reduced peripheral tissue response towards insulin ${ }^{32,33}$. The complications associated with Type 2 diabetes are nephropathy, retinopathy, neuropathy, and cardiovascular disease ${ }^{34}$. The phytochemical treatment in type 2 diabetes has fewer adverse effects and might be considered a better replacement of the existing oral therapy ${ }^{35,36}$. The inclusion of phytoconstituents in combination therapy provides more efficient treatment with significantly decreased side effects in diabetes management ${ }^{37,38}$. The plant's available literature represents that the methanol extract was influential in the treatment of diabetes; however, the study was conducted at pilot scale only, and no reports were available for the responsible specialized metabolites or compounds responsible for its therapeutic activity. Additionally, 


\section{Table 5: Identification of major components in the CAFF fraction of Chenopodium album.}

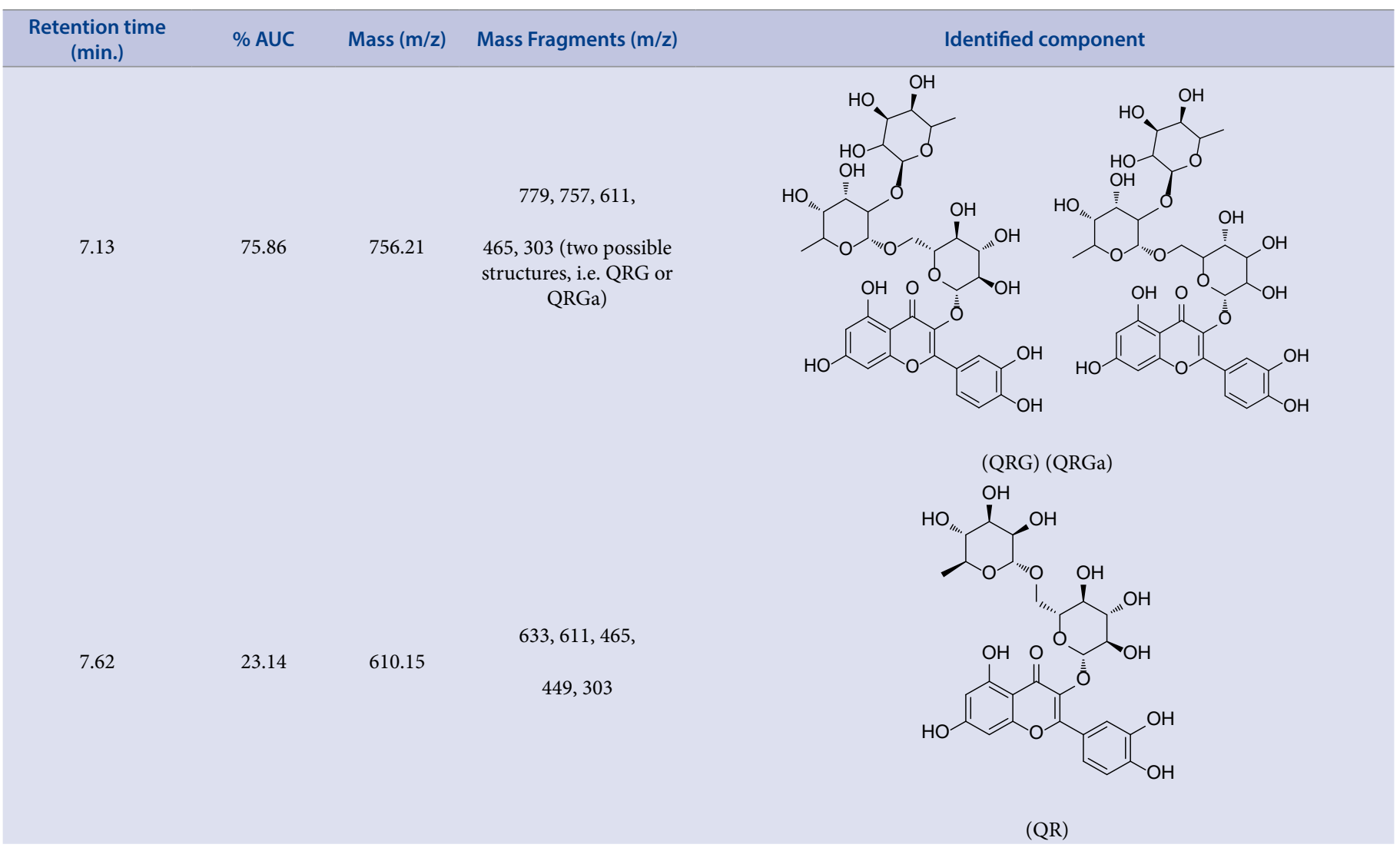

Table 6: Molecular docking results of the bioactive CAFF Fraction.

\begin{tabular}{|c|c|c|c|c|}
\hline \multirow[b]{2}{*}{ S. No. } & \multirow[b]{2}{*}{ Molecule } & \multicolumn{3}{|c|}{ Binding affinity (kcal/mol), RMSD Value $1.5 \mathrm{~A}^{\circ}$} \\
\hline & & $\begin{array}{c}\text { Alpha - glucosidase } \\
\text { (3WY2) }\end{array}$ & $\begin{array}{c}\text { Alpha-amylase } \\
\text { (4GQR) }\end{array}$ & $\begin{array}{c}\text { PPAR gamma } \\
\text { (3SZ1) }\end{array}$ \\
\hline 1 & QRG & -3.9 & -9.3 & -6.0 \\
\hline 2 & QRGa & -6.5 & -9.3 & -7.0 \\
\hline 3 & QR & -5.3 & -8.9 & -6.7 \\
\hline 4 & Acarbose & -4.4 & -6.9 & NA \\
\hline
\end{tabular}

toxicity studies were also not conducted to establish the safety profile of the plant ${ }^{15}$. Therefore, our research mainly focuses on exploring the safety profile, in-vitro and in-vivo antidiabetic potential of the plant at the fraction level, identifies the responsible phytoconstituents, and predicts its plausible mechanism of action.

The plant's aerial parts were fractionated into different fractions and screened for in-vitro alpha-amylase assay. The CAFF fraction showed potent alpha-amylase inhibitor activity compared to standard Acarbose with IC50 values $122.18 \pm 1.15$ and $812.83 \pm 1.07 \mu \mathrm{g} / \mathrm{mL}$, respectively. Other fractions (CATF and CAAF) showed less potent activity. However, the CASF fraction did not produce any significant in-vitro alpha-amylase inhibition activity. Therefore, it is predicated from an alpha-amylase assay that the CAFF fraction plays a vital role in starch and glycogen metabolism, i.e., by decreasing the blood glucose level, thereby reducing the conversion rate of starch to monosaccharides. The fractions (CAFF, CATF, and CAAF) were analyzed for their safety profile based on the alpha-amylase activity. These fractions were screened for acute toxicity at a concentration of $2000 \mathrm{mg} / \mathrm{kg}$, p.o. in albino mice as per OECD guideline 425. The results represent itching for the first 30 min in all the fractions, and afterward, sleepy and drowsing effects were observed in CAFF and CATF fraction. No significant difference was observed in organ body weight index; lesions were not observed in any isolated organs. However, the initial behavioural changes were observed during the first 4 hrs., probably indicating mild toxicity symptoms.

Furthermore, the biochemical parameters represent a significant increase in the lipid profile, i.e., total cholesterol, LDL, VLDL, triglycerides levels; urea in kidney function test; protein, albumin, SGOT/AST levels in liver function test. The increased levels of biochemical parameters in all the fractions indicate the mild toxicity symptoms in CAFF and CATF fractions whereas mild to moderate toxicity symptoms was observed in CAAF fraction.. The hematology parameters also represent the significant increase in the platelets and various blood cells. A significant difference was observed in WBC only in the CAAF fraction in comparison to the control group. These findings indicate the mild toxicity of the fractions. The biochemical results were supported by histopathology results, representing that the fractions (CAFF and CATF) produce mild granular degeneration in the heart, liver, and kidney, whereas the CAAF exhibits mild to moderate granular degeneration in all the organs. Therefore the acute toxicity study indicates that all the fractions have an $\mathrm{LD}_{50}$ more than $2000 \mathrm{mg} /$ $\mathrm{kg}$. Despite this, it is recommended to explore the mechanistic insights for the mild toxicity by performing sub-acute and chronic toxicity of the bioactive fractions with detailed mechanistic studies. 

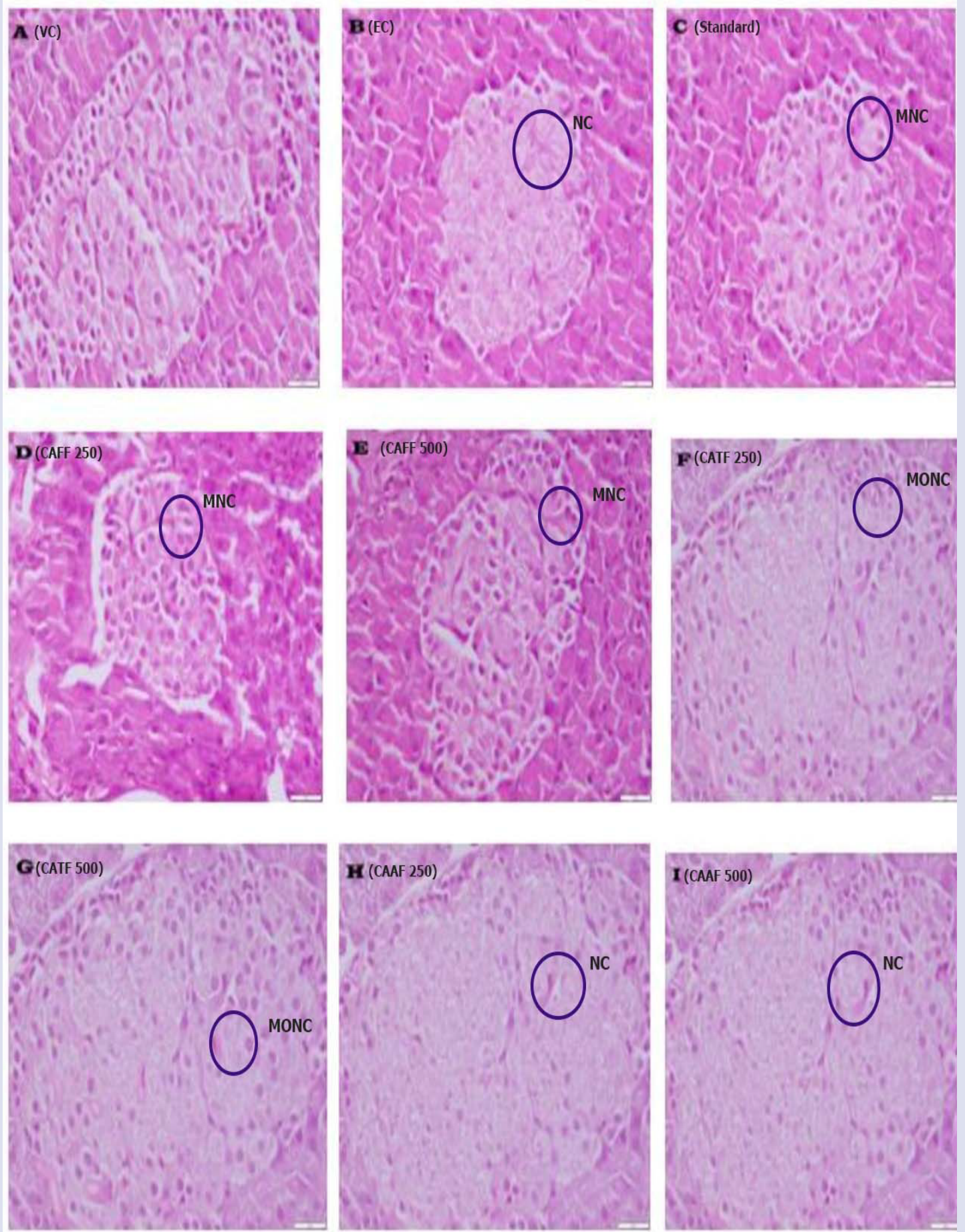

Figure 7: Represents the Histopathological observations of Pancreas, A (VC): Nothing abnormal detected; B(Experimental Control): Necrosis of Islets of Langerhans; C (Standard): Mild necrosis of Islets of Langerhans; D (CAFF $250 \mathrm{mg} / \mathrm{kg}$ ): Mild necrosis of Islets of Langerhans; E (CAFF $500 \mathrm{mg} / \mathrm{kg}$ ): Mild necrosis of Islets of Langerhans; F (CATF $250 \mathrm{mg} / \mathrm{kg}$ ): Moderate degeneration and necrosis of Islets of Langerhans; G (CATF $500 \mathrm{mg} / \mathrm{kg}$ ): Moderate degeneration and necrosis of Islets of Langerhans; H (CAAF $250 \mathrm{mg} / \mathrm{kg}$ ): Necrosis of Islets of Langerhans; I (CAAF $500 \mathrm{mg} / \mathrm{kg}$ ): Necrosis of Islets of Langerhans. 


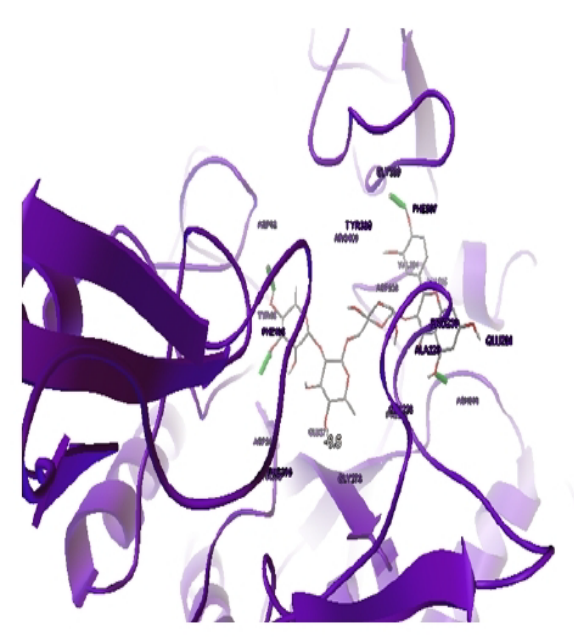

a)

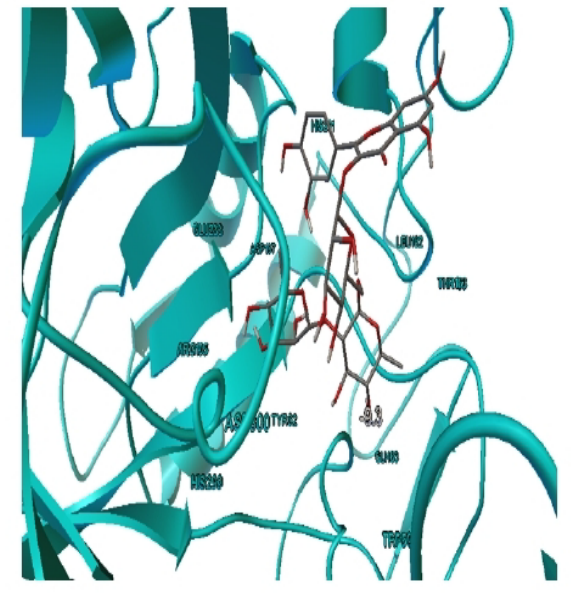

(b)

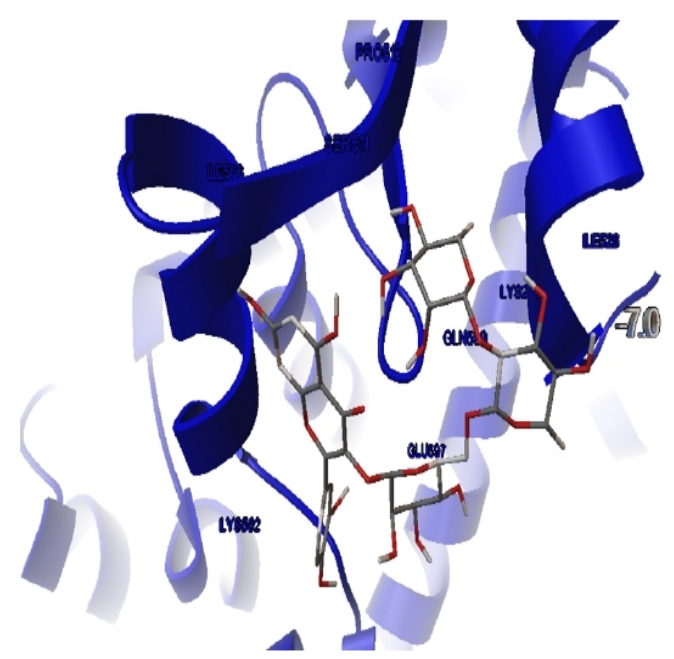

(c)

Figure 8a: Ribbon structure of alpha-glucosidase (purple color) and QRGa in ball and stick model; $\mathbf{b}$. Ribbon structure of alpha-amylase (magenta color) and QRGa in ball and stick model; $\mathbf{c}$. Ribbon structure of PPAR gamma (blue color) and QRGa in ball and stick model.

The fractions (CAFF, CATF, and CAAF) were evaluated for their invivo antidiabetic potential in HFD+ STZ induced Type 2 diabetes. The result represents that after one week of CAFF administration at a 500 $\mathrm{mg} / \mathrm{kg}$ dose, p.o. There is a highly significant decrease in the glucose, cholesterol, and triglyceride level compared with the experimental group, which supports the potential role of CAFF as it was found to be more potent than the standard Acarbose that acts as a positive control. The histopathology findings of the CAFF fraction indicate that the islet of pancreatic cells retains their standard structure, and mild necrosis was observed that supports the potential anti-diabetic effect of the CAFF fraction, whereas, in the CATF fraction, moderate necrosis was observed. However, no recovery is observed in CAAF treated group when compared to the experimental control group. The in-vivo and in-vitro antidiabetic study represent that the CAFF fraction exhibit potential antidiabetic activity among all the fractions.
The highly active fraction CAFF fraction was further explored by LCMS, and three principal components were identified, i.e., $\mathrm{QR}, \mathrm{QRG}$, and QRGa, which are probably responsible for the therapeutic activity of the fraction, reported in Table 5. In literature, these flavonoids QR, QRG, and QRGa are reported for antidiabetic and antioxidant activity ${ }^{39-44}$ and mainly act by interfering in the carbohydrate absorption in the form of glucose and also by assimilation of glucose via insulin release. This represents that due to these flavonoids' presence, the CAFF fraction showed an antidiabetic effect ${ }^{39-44}$.

Thus, to predict the CAFF fraction mechanism, the molecular docking study was carried out against various targets. A detailed interaction for QRGa was studied for alpha-glucosidase, alpha-amylase, and PPAR gamma, respectively. The molecular docking results represent that the QRGa was most active with $-6.5 \mathrm{kcal} / \mathrm{mol},-9.3 \mathrm{kcal} / \mathrm{mol}$, and $-7.0 \mathrm{kcal} /$ mol alpha-glucosidase alpha-amylase, and PPAR gamma, respectively, and it is predicated that CAFF fraction mainly acts as an $\alpha$-amylase inhibitor. 


\section{SUMMARY AND CONCLUSION}

The current study results represent that CAFF fraction was found to possess potent antidiabetic activity dose-dependently in both in vitro and in vivo diabetic models. In contrast, the CATF was less active, and the CAAF fraction did not produce any therapeutic activity. Furthermore, all the fractions did not produce any sign of severe toxicity. Only mild toxicity was observed at a dose of $2000 \mathrm{mg} / \mathrm{kg}$, p. o. In conclusion, the CAFF fraction enhanced the overall diabetic situation by acting as an alpha-amylase inhibitor and further exploring the formulations.

\section{ACKNOWLEDGMENTS}

We thank the management of Lovely Professional University, Phagwara, and PCTE Group of Institutes for providing the necessary support and research facility for conducting the research work. We express our gratitude towards Prof, Dr. Kuldeep Gupta, Department of Veterinary Pathology, Guru Angad Dev University, Ludhiana, for interpretation of histopathology slides and Dr. M.P Singh National Laboratories, Phagwara, for conducting biochemical and hematology analysis.

\section{ABBREVIATIONS}

ALP, Alkaline phosphates; ALT, Alanine aminotransferase; AST, Aspartate aminotransferase; BASO, Basophills; BID, Bilirubin direct; BII, Bilirubin indirect; BIT, Bilirubin total; CMC, Carboxymethyl cellulose; EO, Eosinophils; HCT, Hematocrit; HDL, High-density lipoprotein; HFD, High fat diet; HGB, Hemoglobin; IG, Immature granulocyte count; LDL, Low-density lipoprotein; LYMP, lymphocytes; $\mathrm{MCH}$, mean corpuscular hemoglobin; MCHC, mean corpuscular hemoglobin concentration; MCV, mean corpuscular volume; $\mathrm{MONO}$, Monocytes; MPV, mean platelet volume; NEUT, Neutrophils; P-LCR, Platelet large cell ratio; PCT, Plateletcrit; PDW, Platelet distribution width; PLT, Platelet; RBC, Red blood cells; RDW-CV, Red blood cell distribution width-coefficient of variance; RDW-SD, Red blood cell distribution width- standard deviation; SGOT, Serum glutamic oxaloacetic transaminase; SGPT, Serum glutamic pyruvic transaminase; STZ, Streptozotocin; VLDL, Very low-density lipoprotein; WBC, White blood cells.

\section{CONFLICTS OF INTEREST}

The authors declare no conflicts of interest.

\section{REFERENCES}

1. Domingueti CP, Dusse LMSA, Carvalho MDG, De Sousa LP, Gomes $K B$, Fernandes AP. Diabetes mellitus: The linkage between oxidative stress, inflammation, hypercoagulability and vascular complications. J Diabetes Complications.2016;30:738-45.

2. Cho NH, Shaw JE, Karuranga S, et al. IDF Diabetes Atlas: Global estimates of diabetes prevalence for 2017 and projections for 2045. Diabetes Res Clin Pract. 2018;138:271-281.

3. Abhishek M, Somashekaraiah B V., Dharmesh SM. In vivo antidiabetic and antioxidant potential of Psychotria dalzellii in streptozotocininduced diabetic rats. South African J Bot. 2019;121:494-499.

4. Dharmani M, Kamarulzaman K, Giribabu N, et al. Effect of Marantodes pumilum Blume (Kuntze) var.alata on $\beta$-cell function and insulin signaling in ovariectomised diabetic rats. Phytomedicine. 2019;65:153101.

5. Liu Y, Sun J, Rao S, et al. Antidiabetic activity of mycelia seleniumpolysaccharide from Catathelasma ventricosum in STZ-induced diabetic mice. Food Chem Toxicol. 2013;62: 285-91.

6. Widjajakusuma EC, Jonosewojo A, Hendriati L, et al. Phytochemical screening and preliminary clinical trials of the aqueous extract mixture of Andrographis paniculata (Burm. f.) Wall. ex Nees and Syzygium polyanthum (Wight.) Walp leaves in metformin treated patients with type 2 diabetes. Phytomedicine. 2019; 55:137-147.
7. Balogun FO, Ashafa AOT. Aqueous root extracts of Dicoma anomala (Sond.) extenuates postprandial hyperglycaemia in vitro and its modulation on the activities of carbohydrate-metabolizing enzymes in streptozotocin-induced diabetic Wistar rats. South African J Bot. 2017; 112:102-111.

8. Shah MA, Reanmongkol W, Radenahmad N, Khalil R, UI-Haq Z, Panichayupakaranant P. Anti-hyperglycemic and anti-hyperlipidemic effects of rhinacanthins-rich extract from Rhinacanthus nasutus leaves in nicotinamide-streptozotocin induced diabetic rats. Biomed Pharmacother. 2019;113:108702.

9. Rajasekhar A, Peddanna K, Vedasree N, et al. Antidiabetic activity of root tubers of Asparagus gonoclados Baker in streptozotocin induced diabetic rats. J Ethnopharmacol. 2019;242:112027.

10. Bell DSH. Combine and conquer: Advantages and disadvantages of fixed-dose combination therapy. Diabetes, Obes Metab. 2013; 15:291-30.

11. Prabhakar PK, Kumar A, Doble M. Combination therapy: $A$ new strategy to manage diabetes and its complications. Phytomedicine. 2014; 21: 123-30.

12. Parveen A, Jin M, Kim SY. Bioactive phytochemicals that regulate the cellular processes involved in diabetic nephropathy. Phytomedicine 2018; 39: 146-59.

13. Nowak R, Szewczyk K, Gawlik-Dziki U, Rzymowska J, Komsta $t$. Antioxidative and cytotoxic potential of some Chenopodium $L$. species growing in Poland. Saudi J Biol Sci. 2016; 23(1):15-23.

14. Jain N, Singhai A. Protective effects of Chenopodium album (L.) on ethanol - mediated hepatotoxicity and oxidative stress. Planta Med. 2012;78(11): PI445

15. Kant S, Dua JS, Lather V. Pharmacological evaluation of antidiabetic and antihyperlipidemic activity of Chenopodium album root extract in male Wistar albino rat models. Int J Green Pharm. 2018;12(2):115122.

16. Odhav B, Kandasamy T, Khumalo N, Baijnath H. Screening of African traditional vegetables for their alpha-amylase inhibitory effect. J Med Plants Res. 2010;4(14):1502-1507.

17. Choudhary N, Bijjem KR V., Kalia AN. Antiepileptic potential of flavonoids fraction from the leaves of Anisomeles malabarica. $J$ Ethnopharmacol. 2011;135(2):238-242.

18. Djilani A, Legseir B, Soulimani R, Dicko A, Younos C. New extraction technique for alkaloids. J Braz Chem Soc. 2006;17(3):518-520.

19. Majinda RRT. Chapter 16 Extraction and Isolation of Saponins. Methods Mol Biol. 2012;864:415-426.

20. Bashary R, Khatik GL. Design, and facile synthesis of 1,3 diaryl-3(arylamino)propan-1-one derivatives as the potential alpha-amylase inhibitors and antioxidants. Bioorg Chem. 2019;82:156-162.

21. Cherbal A, Kebieche M, Yilmaz EM, etal. Antidiabetic and hypolipidemic activities of Algerian Pistachia lentiscus L. leaves extract in alloxaninduced diabetic rats. South African J Bot. 2017;108:157-162.

22. Gaikwad AB, Gupta J, Tikoo K. Epigenetic changes and alteration of Fbn1and Col3A1gene expression under hyperglycaemic and hyperinsulinaemic conditions. Biochem J. 2010;432(2):333-341.

23. Srinivasan K, Viswanad B, Asrat L, Kaul CL, Ramarao P. Combination of high-fat diet-fed and low-dose streptozotocin-treated rat: A model for type 2 diabetes and pharmacological screening. Pharmacol Res. 2005;52(4):313-320.

24. Xiong A, Shao $Y$, Fang $L$, et al. Comparative analysis of toxic components in different medicinal parts of Gynura japonica and its toxicity assessment on mice. Phytomedicine. 2019;54:77-88.

25. Saleem U, Amin S, Ahmad B, Azeem H, Anwar F, Mary S. Acute oral toxicity evaluation of aqueous ethanolic extract of Saccharum munja Roxb. roots in albino mice as per OECD 425 TG. Toxicol Reports. 2017:4:580-585

26. Priscilla DH, Roy D, Suresh $A$, Kumar $V$, Thirumurugan K. Naringenin inhibits $\alpha$-glucosidase activity: A promising strategy for the regulation of postprandial hyperglycemia in high fat diet fed streptozotocin induced diabetic rats. Chem Biol Interact. 2014;210(1):77-85. 
27. Gupta J, Gaikwad AB, Tikoo K. Hepatic expression profiling shows involvement of PKC epsilon, DGK eta, Tnfaip, and Rho kinase in type 2 diabetic nephropathy rats. J Cell Biochem. 2010;111(4):944-954.

28. Banerjee S, Bhattacharjee P, Kar A, Mukherjee PK. LC-MS/MS analysis and network pharmacology of Trigonella foenum-graecum - A plant from Ayurveda against hyperlipidemia and hyperglycemia with combination synergy. Phytomedicine. 2019;60:152944.

29. Jang GH, Kim HW, Lee MK, et al. Characterization and quantification of flavonoid glycosides in the Prunus genus by UPLC-DAD-OTOF/MS. Saudi J Biol Sci. 2018;25(8):1622-1631.

30. Kiametis AS, Silva MA, Romeiro LAS, Martins JBL, Gargano R. Potential acetylcholinesterase inhibitors: molecular docking, molecular dynamics, and in silico prediction. J Mol Model 2017; 23, 67-76.

31. Trott O, Olson AJ. Software news and update AutoDock Vina: Improving the speed and accuracy of docking with a new scoring function, efficient optimization, and multithreading. J Comput Chem 2010; 31: 455-61

32. Nie JP, Qu ZN, Chen Y, et al. Discovery and antidiabetic effects of novel isoxazole based flavonoid derivatives. Fitoterapia 2020; 142: 104499.

33. Roden M, Shulman GI. The integrative biology of type 2 diabetes. Nature 2019; 576: 51-60

34. Malik $A$, Ardalani $H$, Anam $S$, et al. Antidiabetic xanthones with $\alpha$-glucosidase inhibitory activities from an endophytic Penicillium canescens. Fitoterapia. 2020;142:104522.

35. Odeyemi S, Bradley G. Medicinal plants used for the traditional management of diabetes in the Eastern Cape, South Africa: Pharmacology and toxicology. Molecules 2018; 23: 2759
36. Choudhury $\mathrm{H}$, Pandey $\mathrm{M}$, Hua $\mathrm{CK}$, et al. An update on natural compounds in the remedy of diabetes mellitus: A systematic review. J Tradit Complement Med 2017; 1-16.

37. Choudhary N, Khatik GL, Suttee A. The possible role of Saponin in Type-II Diabetes- A review. Curr Diabetes Rev. 2020;16.

38. Gaikwad SB, Krishna Mohan G, Sandhya Rani M. Phytochemicals for diabetes management. Pharm Crop. 2014;5:11-28.

39. Bule M, Abdurahman A, Nikfar S, Abdollahi M, Amini M. Antidiabetic effect of quercetin: A systematic review and meta-analysis of animal studies. Food Chem. Toxicol. 2019; 125: 494-02.

40. Braca A, Sinisgalli $C$, De Leo $M$, et al. Phytochemical profile, antioxidant and antidiabetic activities of Adansonia digitata I. (Baobab) from Mali, as a source of health-promoting compounds. Molecules. 2018;23(12):1-18.

41. Borse SP, Singh DP, Upadhyay D, Nivsarkar M. Potential synergistic effects of quercetin with other phytoconstituents of Costus pictus (insulin plant) extract in the control of hyperglycemia and prevention of NSAID-induced gastroenteropathy in diabetic rats. Food Chem Toxicol 2018; 120: 448-61.

42. Ghorbani A. Mechanisms of antidiabetic effects of flavonoid rutin. Biomed Pharmacother. 2017;96:305-312.

43. Mukhopadhyay P, Prajapati AK. Quercetin in antidiabetic research and strategies for improved quercetin bioavailability using polymer-based carriers-a review. RSC Adv. 2015;5(118):97547-62.

44. Can OD, Ozturk Y, Ozturk N, et al. Effects of treatment with St. John's Wort on blood glucose levels and pain perceptions of streptozotocindiabetic rats. Fitoterapia. 2011;82(4):576-584 


\section{GRAPHICAL ABSTRACT}

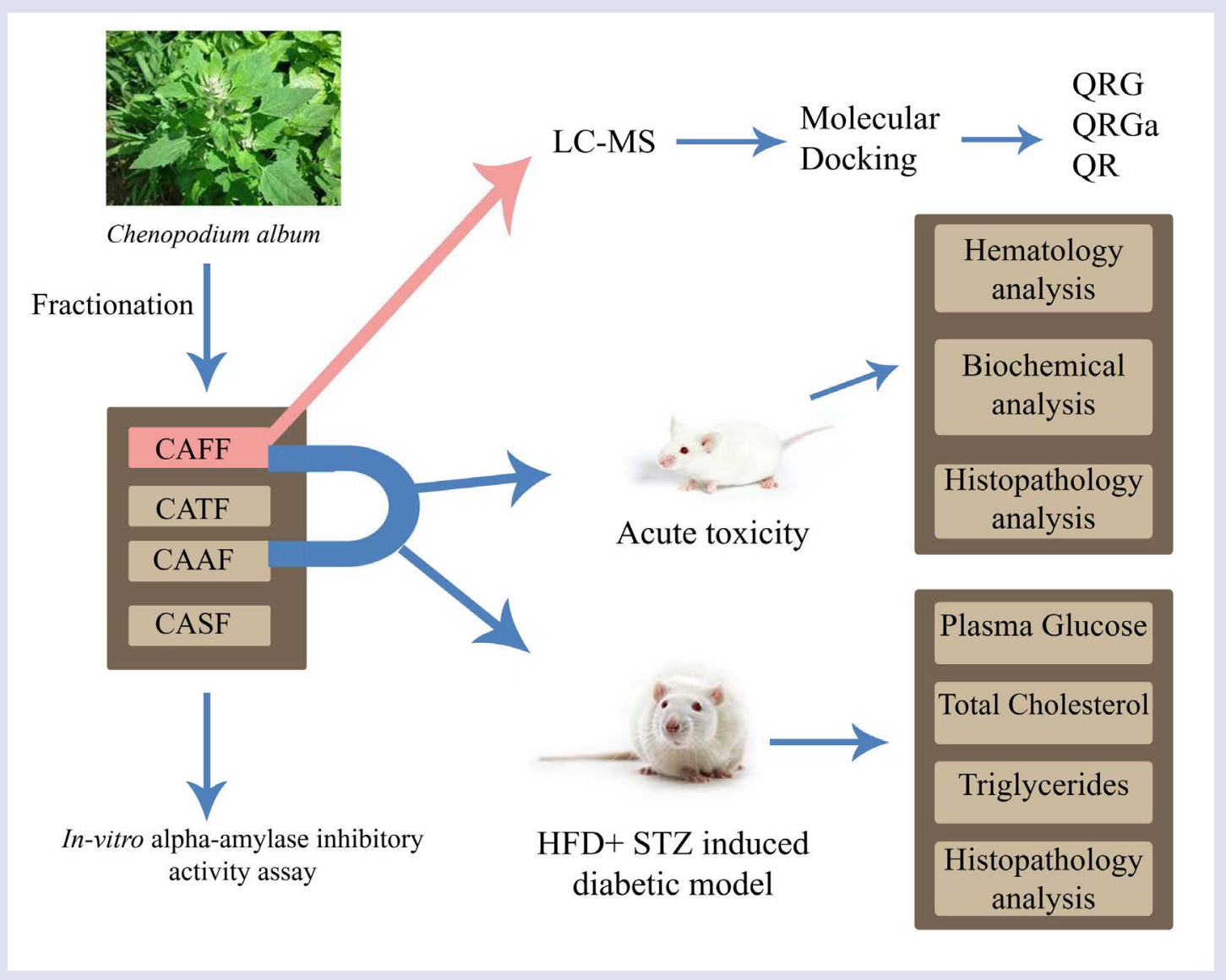

\section{ABOUT AUTHORS}

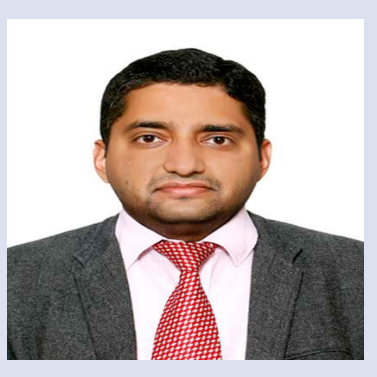

\section{Neeraj Choudhary}

He has been working as an Associate Professor in Department of Pharmacognosy, Faculty of Pharmaceutical Sciences, PCTE Group of Institutes, Ludhiana. My research areas of interest are natural products and herbal drug technology that also extends into identifying, isolation, characterization of phytocostituents from the medicinal plants.

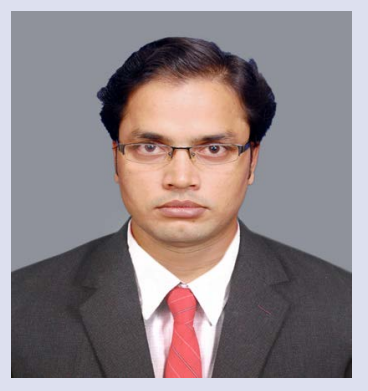

\section{Dr. Pranav Kumar Prabhakar}

Dr Pranav Kumar Prabhakar has received his PhD in Biotechnology from Indian Institute of Technology (IIT) Madras, India during the period of 2011 and he has completed his master in biochemistry from Patna University Bihar, India in 2003. Currently, he is working as Assistant Professor in Lovely Professional University Punjab, India. His research includes included synergy, Phytomedicine, metabolic disorders. He is serving as an editorial member of several reputed journals and expert Reviewers for many journals. He has authored $50+$ research articles/books/ book chapters. He is a member of Royal Society of Chemistry and Asia-Pacific Chemical, Biological \& Environmental Engineering Society (APCBEES). 

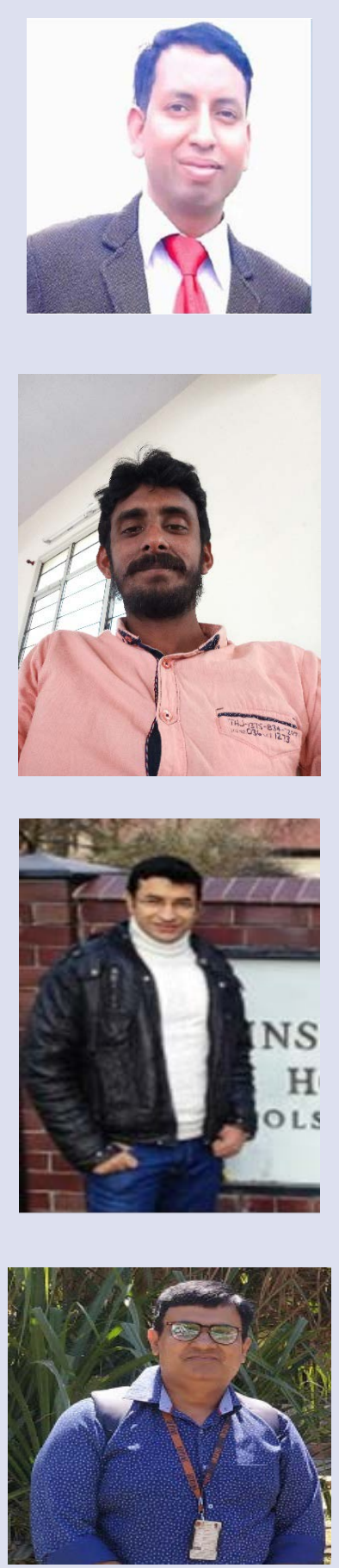

\section{Dr. Gopal L. Khatik}

Dr. Gopal L. Khatik is currently working as an Assistant Professor at the National Institute of Pharmaceutical Education \& Research (NIPER) Raebareli. He was previously associated with Lovely Professional University as an Associate Professor in the School of Pharmaceutical Sciences. He had been received his Ph.D. in 2012 from NIPER-Mohali. His research interest is drug design, computational techniques, synthetic and medicinal chemistry. He had been authored more than 70+ research and review articles including books and book chapters. $\mathrm{He}$ is a member of CRSI, IPA, IPGA, ISCA, ISPOR, and SPER.

\section{SUBBA RAO CHAMAKURI}

Subba Rao Chamakuri is a Pursuing Ph. D at Lovely Professional Universiy, Jalandhar, Punjab, India. He has a pursuing PhD in Hepatoprotective activity from Lovely Professional University. His research focus is non-communicable diseases especially on Liver.

\section{DR. DEVESH TEWARI}

Researcher In The Field Of Natural Product Drug Discovery, Pharmacognosy, And Ayurvedic Pharmacognosy With Main Focus In Exploration Of Medicinal Plants Of The Himalayan Region Through Ethnopharmacology And Reverse Pharmacology Approach. Significant Research Achievements In The Field Of Pharmacological Validation And Phytochemistry Of Western Himalayan Plants With A Cumulative Impact Factor (Jcr Clarivate Analytics) Of Over 250 For Published Papers.

\section{DR. ASHISH SUTTEE}

Dr. Ashish Suttee is currently working as an Associate Professor at the School of Pharmaceutical Sciences, Lovely Professional University, Punjab, India. His primary research interest is exploration, standardization and screening of medicinal plants (in vitro, in vivo and molecular docking ) as potential therapeutic interventions for the treatment of diabetes and liver diseases. He had been authored more than $30+$ research and review articles including book chapters. He is a member of APTI, IPA, and IPCA.

Cite this article: Choudhary N, Prabhakar PK, Khatik GL, Chamakuri SR, Tewari D, Suttee A. Evaluation of Acute toxicity, In-vitro, In-vivo Antidiabetic Potential of the Flavonoid Fraction of the plant Chenopodium album L. Pharmacog J. 2021;13(3): 765-79. 